\title{
Analisis Pola Operasi Weekday MRT Jakarta Berdasarkan Kepadatan Penumpang
}

\author{
Uned Supriadi, Bagas Setyoning Adji, Widorisnomo \\ KERETA API INDONESIA PERSERO \\ Email: unedsupriadi68@gmail.com
}

\begin{abstract}
Abstrak
Transportasi merupakan urat nadi dalam setiap kehidupan masayarakat. Pergerakan masyarakat tidak akan dapat berjalan dengan lancar tanpa adanya sarana transportasi sehingga akan berpengaruh kepada pertumbuhan ekonomi. Akan tetapi seiring dengan perkembangan zaman pergerakan masyarakat dalam berpindah tempat setiap hari telah menyebabkan terjadinya kemacetan di jalan raya. Pertumbuhan kendaraan pribadi tidak seiring dengan luasnya jalan raya. Oleh sebab itu pemerintah mulai memikirkan penggunaan moda transportasi yang murah dan mampu mengangkut orang dalam jumlah banyak yang salah satu diantaranya adalah kereta api dan MRT. Penelitian ini berusaha untuk menganalisis pola operasi weekday MRT Jakarta berdasarkan kepadatan penumpang. Penelitian ini menggunakan pendekatan literatur yaitu suatu metode pengumpulan data dan informasi berdasarkan buku-buku referensi maupun peraturan yang ada dan berlaku. Data yang diperlukan terlebih dahulu dalam menunjang penelitian adalah data sekunder maupun data primer, yang kemudian akan dilakukan analisis untuk mencari permasalahan yang ada serta mencari penyelesaian masalah tersebut. Hasil penelitian menunjukkan peningkatan jumlah penumpang pada pukul 18:00 19:00 WIB sebesar $104 \%$ dengan kebutuhan armada sebanyak 14 stamformasi dan jumlah perjalanan sebanyak 19 perjalanan dan antara pukul 19:00 - 20:00 WIB sebesar 120\% dengan headway 10 menit dapat di perkecil menjadi headway 7 menit dengan jumlah perjalanan sebanyak 13 perjalanan.
\end{abstract}

Kata Kunci: Pola Operasi, MRT, Kepadatan Penumpang

\begin{abstract}
Transportation is the lifeblood of every community. The movement of people will not be able to run smoothly without the means of transportation so that it will affect economic growth. However, along with the times, the movement of people in changing places every day has caused congestion on the highway. The growth of private vehicles is not in line with the width of the highway. Therefore, the government is starting to think about the use of transportation modes that are cheap and capable of transporting large numbers of people, one of which is the train and MRT. This study seeks to analyze the pattern of weekday MRT Jakarta operations based on passenger density. This study uses a literature approach, which is a method of collecting
\end{abstract}


data and information based on reference books and existing and applicable regulations. The first data needed to support research is secondary data and primary data, which will then be analyzed to find existing problems and find solutions to these problems. The results showed an increase in the number of passengers at 18:00 - 19:00 WIB by 104\% with a fleet requirement of 14 stamformations and a total of 19 trips and between 19:00 - 20:00 WIB by $120 \%$ with a 10-minute headway. reduced to a 7-minute headway with a total of 13 trips.

\section{Keywords: Operation Pattern, MRT, Passenger Density}

\section{A. PENDAHULUAN}

Transportasi di Indonesia memegang peranan yang sangat penting dalam sendi kehidupan masayarakat. Pergerakan masyarakat dalam perpindah tempat setiap hari selalu menjadi penyebab kemacetan di jalan raya. Dengan semakin banyak penggunaan kendaraan pribadi tidak sebanding dengan luasnya jalan raya. Seiring dengan perkembangan jaman, proses transportasi sebagai alat angkut mengalami perkembangan kemajuan. Sebagai sebuah transportasi massal, yang mampu mengangkut penumpang dan barang dalam jumlah banyak serta murah, kereta api menjadi salah satu alternatif transportasi darat.

DKI Jakarta merupakan provinsi dengan memiliki jumlah penduduk yang padat. Dengan bertambahnya penduduk tiap tahun dan tidak didukung dengan perkembangan moda transportasi massal maka akan menyebabkan masalah kemacetan dimana-mana. MRT Jakarta hadir untuk memberikan solusi tersebut. Mass Rapid Transit Jakarta adalah salah satu dari berbagai jenis moda transportasi perkeretapiaan yang berada di Provinsi DKI Jakarta. Mass Rapid Transit (MRT) Jakarta pada fase pertama beroperasi mulai bulan Maret 2019 dengan lintas dari Lebak Bulus sampai dengan Bundaran HI.

MRT Jakarta dalam operasi memberlakukan weekday dan weekend. Weekday adalah waktu operasi yang diberlakukan pada hari Senin sampai dengan hari Jum'at. Weekend adalah waktu operasi yang diberlakukan pada hari Sabtu dan hari Minggu. Weekday juga memberlakukan peak hour dan off peak hour. Peak hour adalah jam sibuk yang dimana diberlakukan headway 5 menit. Dan off peak hour adalah jam normal atau jam diluar jam sibuk yang diberlakukan headway 10 menit. Namun berdasarkan data volume jumlah penumpang terjadi peningkatan jumlah penumpang pada pukul 18:00 - 19:00 WIB dari bulan September 2019-Februari 2020 sebesar 104 $\%$ dan jumlah peningkatan jumlah penumpang pada pukul 19:00 - 20:00 WIB dari bulan September - Februari 2020 sebesar $120 \%$. Dengan kapasitas penumpang KA MRT Jakarta 920 penumpang/KA dan kurangnya jumlah perjalanan KA MRT Jakarta terdapat penumpang yang tidak terangkut pada pukul 18:00 - 19:00 dari 22 penumpang pada bulan September 2019 tidak terangkut sampai dengan 1951 penumpang pada bulan Februari 2020. Dan penumpang tidak terangkut pada pukul 19:00 - 20:00 dari 1490 penumpang pada bulan September 2019 tidak terangkut sampai dengan 3258 penumpang pada bulan Februari 2020.

Hal tersebut disebabkan oleh waktu tempuh yang masih tergolong lama yang mana dapat dipersingkat apabila menambahkan kecepatan rata - rata KA MRT Jakarta lintas Lebak Bulus Bundaran HI pada pukul 18:00 - 20:00 WIB. Dan kurangnya jumlah perjalanan KA dan kebutuhan armada pada pukul 18:00 - 19:00 WIB. Serta perlunya memperkecil headway dan menambahkan jumlah perjalanan KA MRT Jakarta pada pukul 19:00 - 20:00 WIB. 
Oleh sebab itu, maka dalam penyusunan Kertas Kerja Wajib ini dapat diambil judul "Analisis Pola Operasi Weekday Mrt Jakarta Berdasarkan Kepadatan Penumpang".

\section{B. METODE}

Metode yang dipakai dalam penelitian ini merupakan Penelitian Literatur yaitu suatu metode pengumpulan data dan informasi berdasarkan buku-buku referensi maupun peraturan yang ada dan berlaku. Data yang diperlukan terlebih dahulu dalam menunjang penelitian adalah data sekunder maupun data primer, yang kemudian akan dilakukan analisis untuk mencari permasalahan yang ada serta mencari penyelesaian masalah tersebut. Data primer merupakan kunci utama dalam melakukan penelitian, karena didapat dari hasil pengamatan langsung dilapangan mengenai pengoperasian KA MRT Jakarta. Data sekunder merupakan data yang diperoleh dari instansi-instansi terkait, dan penelusuran literatur yang sesuai dengan kebutuhan analisis. Data tersebut digunakan untuk mendukung dan menjadi pelengkap bagi data primer dalam melakukan analisis terhadap permasalahan. Data-data tersebut diambil dari instansi terkait yang akan digunakan dalam penelitian ini. Penelitian dilakukan di wilayah pengoperasian MRT Jakarta dengan lintas Lebak Bulus - Bundaran HI. Waktu yang dilaksanakan oleh penulis dalam melakukan penelitian yaitu pada saat kerja lapangan tanggal 3 Februari 2020 - 18 Februari 2020. Alat penelitian yang digunakan untuk melakukan penelitian ini antara lain : alat tulis, buku tulis dan kamera.

\section{HASIL DAN PEMBAHASAN}

\section{Analisis Karakterisik Penumpang yang Menggunakan MRT}

Berdasarkan survey yang telah dilaksanakan 13 hari pada 13 stasiun MRT Jakarta. Yang mana 1 hari pelaksanaan survey dilakukan selama 2 jam mulai pukul 18:00 sampai dengan 20:00 WIB. Sehingga didapat 300 responden selama 13 hari survey dan diadakan pada 13 stasiun MRT Jakarta. Berikut beberapa hasil survey pada pukul 18:00 - 20:00 WIB antara lain:

1. Berdasarkan hasil survey tersebut, menunjukan sampel yang mana penumpang paling banyak sebagai karyawan swasta sebesar $39 \%$. Selanjutnya sebagai anggota POLRI/TNI sebesar $20 \%$. Kemudian sebagai pegawai BUMN sebesar $15 \%$. Setelah itu, sebagai wiraswasta sebesar $7 \%$, pelajar sebesar $12 \%$ dan PNS sebesar $7 \%$ serta pensiunan sebesar $2 \%$.

2. Berdasarkan hasil survey, sampel yang mana menunjukkan bahwa sebagian besar penumpang MRT Jakarta berusia antara 31 - 40 tahun dengan persentase sebesar $33 \%$. Kemudian penumpang dengan usia 21 - 30 tahun dengan persentase sebesar $29 \%$. Selanjutnya penumpang dengan usia antara $41-50$ tahun dengan persentase $26 \%$. Lalu disusul penumpang dengan usia antara $11-20$ tahun persentase sebesar $6 \%$, pada usia antara 51 -60 tahun dengan persentase sebesar $4 \%$, dan pada usia penumpang $>60$ tahun dengan persentase sebesar $2 \%$.

3. Dari hasil survei juga dapat diketahui menunjukkan bahwa maksud perjalanan paling banyak adalah kerja sebesar $57 \%$. Kemudian maksud perjalanan rekreasi sebesar $10 \%$. Lalu maksud perjalanan olahraga sebesar $30 \%$. Dan maksud perjalanan belanja sebesar 3 $\%$.

4. Berdasarkan hasil survey, menunjukkan bahwa alasan penumpang memilih MRT Jakarta adalah lebih cepat sebesar $90 \%$. Kemudian alasan lainnya kenapa penumpang memilih MRT Jakarta adalah nyaman sebesar $5 \%$. Selanjutnya disusul dengan alasan murah sebesar $3 \%$ dan aman sebesar $2 \%$. Berdasarkan survey tersebut, didapat karakteristik dari 
penumpang yang menggunakan MRT Jakarta dan lebih memilih MRT Jakarta daripada transportasi lainnya yang menyebabkan penumpukan penumpang pada pukul 18:00 - 20:00 WIB.

Berdasarkan data tersebut, masih terdapat penumpang yang tidak terangkut. Hal ini disebabkan terjadi peningkatan jumlah penumpang yang tidak terangkut pada pukul 19:00 sampai dengan 20:00 WIB. Peningkatan tersebut begitu signifikan dari bulan September dengan jumlah penumpang yang tidak terangkut sebesar 1490 penumpang sampai dengan bulan Februari 2020 dengan jumlah 3258 penumpang.

Menurut survey dan analisis yang telah penulis lakukan pada pukul 18:00 - 20:00 WIB, terdapat perbedaan waktu tempuh antara MRT Jakarta dengan moda transportasi Jakarta lainnya. Semakin padat lalu lintas semakin banyak pilihan transportasi untuk mengurai kemacetan di Ibukota DKI Jakarta. Sehingga penulis melakukan pengamatan perbedaan waktu tempuh MRT Jakarta dengan moda transportasi lainnya melalui survey secara langsung di lapangan. Dari hasil pengukuran terbukti bahwa MRT Jakarta yang beroperasi lintas operasi Lebak Bulus - Bundaran HI hanya membutuhkan waktu tempuh 30 menit. Lebih cepat daripada bus transjakarta, kendaraan pribadi maupun bus pengumpan. Sehingga korelasi antara hasil survey penumpang dengan survey pengamatan waktu tempuh transportasi Jakarta mempunyai hubungan alasan kenapa pengguna jasa memilih MRT Jakarta.

\section{Pembahasan Pola Operasi Weekday}

a. Penambahan Jumlah Perjalanan Pukul 18:00 - 19:00 WIB

MRT Jakarta beroperasi dari pukul 05:00 sampai dengan 24:00 WIB. Berikut tabel perjalanan dan headway pada pukul 05:00 - 24:00 WIB.

Tabel 1. Jumlah Perjalanan Dan Headway Weekday

\begin{tabular}{|c|c|c|c|}
\hline Waktu & $\begin{array}{c}\text { Jumlah Trip } \\
\text { ( Perjalanan })\end{array}$ & $\begin{array}{c}\text { Headway } \\
\text { ( menit })\end{array}$ & $\begin{array}{c}\text { Jumlah KA Yang } \\
\text { Beroperasi } \\
\text { ( KA ) }\end{array}$ \\
\hline 05:00 - 06:00 & 12 & 10 & 7 \\
\hline 06:00 - 07:00 & 16 & 10 & 12 \\
\hline 07:00 - 08:00 & 23 & 5 & 14 \\
\hline 08:00 - 09:00 & 23 & 5 & 14 \\
\hline 09:00 - 10:00 & 17 & 10 & 9 \\
\hline 10:00 - 11:00 & 13 & 10 & 7 \\
\hline 11:00 - 12:00 & 12 & 10 & 7 \\
\hline 12:00 - 13:00 & 12 & 10 & 7 \\
\hline $13: 00-14: 00$ & 12 & 10 & 8 \\
\hline $14: 00-15: 00$ & 12 & 10 & 10 \\
\hline 15:00 - 16:00 & 15 & 10 & 14 \\
\hline $16: 00-17: 00$ & 21 & 10 & 10 \\
\hline 17:00 - 18:00 & 24 & 5 & 7 \\
\hline 18:00 - 19:00 & 19 & 5 & 7 \\
\hline 19:00 - 20:00 & 13 & 10 & 7 \\
\hline 20:00 - 21:00 & 12 & 10 & \\
\hline 21:00 - 22:00 & 12 & 10 & \\
\hline
\end{tabular}


Vol. 11 No. 2 (2020): Jurnal Penelitian Sekolah Tinggi Transportasi Darat

\begin{tabular}{|c|c|c|c|}
\hline $22: 00-23: 00$ & 12 & 10 & 7 \\
\hline $23: 00-24: 00$ & 5 & 10 & 3 \\
\hline
\end{tabular}

Sumber : Grafik Perjalanan KA Weekday MRT Jakarta, 2020

Berdasarkan Gapeka Weekday tersebut yang mana hanya pada pukul 18:00 - 19:00 WIB yang memiliki jumlah perjalanan yang lebih sedikit dari pada 3 jam sibuk lainnya. Berikut tabel perbandingan okupansi KA 4 jam sibuk :

Tabel 2. Perbandingan Okupansi Pada 4 Jam Sibuk

\begin{tabular}{|c|c|c|c|c|c|c|}
\hline \multirow{2}{*}{ Waktu } & \multicolumn{7}{|c|}{ Okupansi Rata - } \\
Rata \\
\cline { 2 - 7 } & $\begin{array}{c}\text { Septemb } \\
\text { er }\end{array}$ & Oktober & $\begin{array}{c}\text { Novemb } \\
\text { er }\end{array}$ & Desember & $\begin{array}{c}\text { Janua } \\
\text { ri }\end{array}$ & $\begin{array}{c}\text { Februa } \\
\text { ri }\end{array}$ \\
\hline $07: 00-08: 00$ & $39 \%$ & $40 \%$ & $39 \%$ & $39 \%$ & $36 \%$ & $31 \%$ \\
\hline $08: 00-09: 00$ & $49 \%$ & $50 \%$ & $50 \%$ & $50 \%$ & $49 \%$ & $48 \%$ \\
\hline $17: 00-18: 00$ & $67 \%$ & $70 \%$ & $77 \%$ & $80 \%$ & $83 \%$ & $86 \%$ \\
\hline $18: 00-19: 00$ & $100 \%$ & $101 \%$ & $103 \%$ & $106 \%$ & $108 \%$ & $111 \%$ \\
\hline
\end{tabular}

Sumber : Hasil Analisis, 2020

Berdasarkan tabel tersebut, okupansi pada pukul 18:00 - 19:00 lebih besar dari pada 3 jam sibuk lainnya. Berdasarkan hasil perhitungan, diperlukan penambahan kebutuhan sarana dengan tambahan 4 KA sehingga menjadi 14 KA yang dioperasikan pada pukul 18:00 - 19:00 WIB. Perlu adanya tambahan jumlah perjalanan dengan tambahan 3 perjalanan sehingga menjadi 21 perjalanan pada pukul 18:00 - 19:00 WIB.

b. Penambahan Jumlah Perjalanan Pada Pukul 19:00 - 20:00 WIB

Pukul 19:00 - 20:00 WIB, merupakan jam off peak hour yang beroperasi pada weekday. Akan tetapi di lapangan, pukul 19:00 -20:00 merupakan waktu yang paling ramai penumpang yang menggunakan jasa MRT Jakarta. Peak Hour pagi berlaku pada pukul 07:00 - 09:00 WIB dan pada petang hari berlaku pada pukul 17:00 - 19:00 WIB. Berikut perbandingan volume kepadatan penumpang dari pukul 05:00 - 24:00 WIB.

Tabel 3 Perbandingan Volume Kepadatan Penumpang

\begin{tabular}{|c|c|c|c|c|c|c|}
\hline \multirow{2}{*}{ Waktu } & \multicolumn{5}{|c|}{$\begin{array}{c}\text { Volume Kepadatan Penumpang } \\
\text { (penumpang ) }\end{array}$} \\
\cline { 2 - 8 } & & & & & & \\
& September & Oktober & November & Desember & Januari & $\begin{array}{c}\text { Februar } \\
\text { i }\end{array}$ \\
\hline $\mathbf{0 5 : 0 0 - 0 6 : 0 0}$ & 209 & 237 & 245 & 221 & 255 & 216 \\
\hline $\mathbf{0 6 : 0 0}-\mathbf{0 7 : 0 0}$ & 2297 & 2407 & 2339 & 2212 & 2309 & 2030 \\
\hline $\mathbf{0 7 : 0 0}-\mathbf{0 8 : 0 0}$ & 8188 & 8444 & 8262 & 8328 & 7710 & 6562 \\
\hline $\mathbf{0 8 : 0 0}-\mathbf{0 9 : 0 0}$ & 10371 & 10607 & 10536 & 10476 & 10433 & 10165 \\
\hline $\mathbf{0 9 : 0 0 - 1 0 : 0 0}$ & 6130 & 6292 & 6238 & 6490 & 7288 & 8871 \\
\hline $\mathbf{1 0 : 0 0 - 1 1 : 0 0}$ & 3195 & 3445 & 3330 & 3754 & 5028 & 5694 \\
\hline
\end{tabular}


Vol. 11 No. 2 (2020): Jurnal Penelitian Sekolah Tinggi Transportasi Darat

\begin{tabular}{|c|c|c|c|c|c|c|}
\hline $\mathbf{1 1 : 0 0}-\mathbf{1 2 : 0 0}$ & 3142 & 3124 & 3078 & 3868 & 4894 & 4655 \\
\hline $\mathbf{1 2 : 0 0}-\mathbf{1 3 : 0 0}$ & 3791 & 3683 & 3582 & 4560 & 4661 & 3902 \\
\hline $\mathbf{1 3 : 0 0}-\mathbf{1 4 : 0 0}$ & 3919 & 3844 & 3812 & 4568 & 4489 & 4234 \\
\hline $\mathbf{1 4 : 0 0}-\mathbf{1 5 : 0 0}$ & 3374 & 3300 & 3204 & 4089 & 4102 & 3995 \\
\hline $\mathbf{1 5 : 0 0}-\mathbf{1 6 : 0 0}$ & 3401 & 3536 & 3224 & 3780 & 4376 & 4833 \\
\hline $\mathbf{1 6 : 0 0}-\mathbf{1 7 : 0 0}$ & 5097 & 5284 & 4974 & 5417 & 5675 & 6321 \\
\hline $\mathbf{1 7 : 0 0}-\mathbf{1 8 : 0 0}$ & 14894 & 15512 & 17016 & 17611 & 18285 & 19078 \\
\hline $\mathbf{1 8 : 0 0}-\mathbf{1 9 : 0 0}$ & 17502 & 17697 & 18071 & 18458 & 18907 & 19431 \\
\hline $\mathbf{1 9 : 0 0}-\mathbf{2 0}: 00$ & 13450 & 13883 & 14242 & 14677 & 14937 & 15218 \\
\hline $\mathbf{2 0 : 0 0}-\mathbf{2 1 : 0 0}$ & 5689 & 5088 & 5596 & 6212 & 5919 & 4024 \\
\hline $\mathbf{2 1 : 0 0}-\mathbf{2 2 : 0 0}$ & 3849 & 3446 & 3728 & 4329 & 4474 & 2735 \\
\hline $\mathbf{2 2 : 0 0}-\mathbf{2 3}: 00$ & 2442 & 2152 & 2290 & 2733 & 2022 & 1597 \\
\hline $\mathbf{2 3 : 0 0}-\mathbf{2 4 : 0 0}$ & 694 & 635 & 763 & 890 & 665 & 521 \\
\hline
\end{tabular}

Berdasarkan tabel okupansi tersebut, maka diperlukan penambahan jumlah trip dan memperkecil headway Berdasarkan hasil perhituingan jumlah perjalanan pukul 19:00 -20:00 WIB perlu ditambah 4 perjalanan sehingga menjadi 17 perjalanan dengan headway 7 menit dengan kebutuhan sarana 10 KA. Perlu adanya penambahan jumlah perjalanan KA MRT Jakarta sehingga dapat mengangkut penumpang yang tidak terangkut. Berikut tabel setelah dilakukan perhitungan pukul 18:00 - 20:00 WIB :

Tabel 4. Jumlah Perjalanan Setelah Dilakukan Penelitian

\begin{tabular}{|c|c|c|c|}
\hline Waktu & $\begin{array}{c}\text { Jumlah Trip } \\
\text { (Perjalanan })\end{array}$ & $\begin{array}{c}\text { Headway } \\
\text { (menit })\end{array}$ & $\begin{array}{c}\text { Jumlah KA Yang } \\
\text { Beroperasi } \\
\text { ( KA })\end{array}$ \\
\hline $05: 00-06: 00$ & 12 & 10 & 7 \\
\hline $06: 00-07: 00$ & 16 & 10 & 12 \\
\hline $07: 00-08: 00$ & 23 & 5 & 14 \\
\hline $08: 00-09: 00$ & 23 & 5 & 14 \\
\hline $09: 00-10: 00$ & 17 & 10 & 9 \\
\hline $10: 00-11: 00$ & 13 & 10 & 7 \\
\hline $11: 00-12: 00$ & 12 & 10 & 7 \\
\hline $12: 00-13: 00$ & 12 & 10 & 7 \\
\hline $13: 00-14: 00$ & 12 & 10 & 10 \\
\hline $14: 00-15: 00$ & 12 & 10 & 14 \\
\hline $15: 00-16: 00$ & 15 & 10 & 14 \\
\hline $16: 00-17: 00$ & 21 & 10 & 10 \\
\hline $17: 00-18: 00$ & 24 & 5 & 7 \\
\hline $18: 00-19: 00$ & 21 & 5 & 7 \\
\hline $19: 00-20: 00$ & 17 & 7 & 7 \\
\hline $20: 00-21: 00$ & 12 & 10 & 3 \\
\hline $21: 00-22: 00$ & 12 & 10 & \\
\hline $22: 00-23: 00$ & 12 & 10 & 14 \\
\hline $23: 00-24: 00$ & 5 & 10 & \\
\hline
\end{tabular}


Sumber : Hasil Analisis, 2020

\section{c. Perbandingan Jumlah Penumpang Yang Tidak Terangkut Setelah Dilakukan Penelitian}

Berdasarkan analisis tersebut, setelah dilakukan penambahan jumlah perjalanan pada pukul 18:00 -19:00 WIB dan pukul 19:00 -20:00 WIB. Penumpang yang tidak terangkut sebelumnya, dan meningkatkan kapasitas angkut penumpang. Berdasarkan perhitungan penumpang tidak terangkut yang didapat dari hasil kapasitas penumpang dikalikan jumlah perjalanan dikurangi jumlahpenumpang pada waktu tertentu. Untuk membandingkan anatara sebelum adanya penambahan perjalanan dengan setelah adanya penambahan perjalanan pada pukul 18:00 - 20:00 WIB. Berikut tabel perbandingan jumlah penumpang yang tidak terangkut :

Tabel 5. Perbandingan Jumlah Penumpang Tidak Terangkut ada pukul 18:00 -19:00 WIB

\begin{tabular}{|c|c|c|c|c|c|c|c|c|}
\hline \multirow{2}{*}{ NO. } & \multirow{2}{*}{ BULAN } & \multirow{2}{*}{$\begin{array}{c}\text { AW 2 } \\
\text { (PNP) }\end{array}$} & & \multicolumn{2}{|c|}{ Sebelum Penambahan Trip } & \multicolumn{2}{c|}{ Setelah Penambahan Trip } \\
\cline { 5 - 9 } & & & $\begin{array}{c}\text { JUMLAH } \\
\text { TRIP }\end{array}$ & $\begin{array}{c}\text { JUMLAH } \\
\text { PNP }\end{array}$ & $\begin{array}{c}\text { PNP TDK } \\
\text { TERANG } \\
\text { KUT }\end{array}$ & $\begin{array}{c}\text { JUMLAH } \\
\text { TRIP }\end{array}$ & $\begin{array}{c}\text { JUML } \\
\text { AH PNP }\end{array}$ & $\begin{array}{c}\text { PNP } \\
\text { TDK } \\
\text { TERAN } \\
\text { GKUT }\end{array}$ \\
\hline 1 & SEPTEMBER & 920 & 19 & 17502 & 22 & 21 & 17502 & -1818 \\
\hline 2 & OKTOBER & 920 & 19 & 17697 & 217 & 21 & 17697 & -1623 \\
\hline 3 & NOVEMBER & 920 & 19 & 18071 & 591 & 21 & 18071 & -1249 \\
\hline 4 & DESEMBER & 920 & 19 & 18458 & 978 & 21 & 18458 & -862 \\
\hline 5 & JANUARI & 920 & 19 & 18907 & 1427 & 21 & 18907 & -413 \\
\hline 6 & FEBRUARI & 920 & 19 & 19318 & 1951 & 21 & 19318 & -2 \\
\hline
\end{tabular}

Sumber : Hasil Analisis, 2020

Tabel 6. Perbandingan Jumlah Penumpang Tidak Terangkut Pada Pukul 19:00 -20:00 WIB.

\begin{tabular}{|c|c|c|c|c|c|c|c|c|}
\hline \multirow{2}{*}{ NO. } & \multirow{2}{*}{ BULAN } & \multirow{2}{*}{$\begin{array}{l}\text { AW 2 } \\
\text { (PNP) }\end{array}$} & \multicolumn{2}{|c|}{ Sebelum Penambahan Trip } & \multicolumn{2}{c|}{ Setelah Penambahan Trip } \\
\cline { 4 - 10 } & & & $\begin{array}{c}\text { JUMLA } \\
\text { H TRIP }\end{array}$ & $\begin{array}{c}\text { JUMLAH } \\
\text { PNP }\end{array}$ & $\begin{array}{c}\text { PNP } \\
\text { TDK } \\
\text { TERAN } \\
\text { GKUT }\end{array}$ & $\begin{array}{c}\text { JUMLAH } \\
\text { TRIP }\end{array}$ & $\begin{array}{c}\text { JUML } \\
\text { AH PNP }\end{array}$ & $\begin{array}{c}\text { PNP } \\
\text { TDK } \\
\text { TERAN } \\
\text { GKUT }\end{array}$ \\
\hline 1 & SEPTEMBER & 920 & 13 & 13450 & 1490 & 17 & 13450 & -2190 \\
\hline 2 & OKTOBER & 920 & 13 & 13883 & 1923 & 17 & 13883 & -1757 \\
\hline 3 & NOVEMBER & 920 & 13 & 14242 & 2282 & 17 & 14242 & -1398 \\
\hline 4 & DESEMBER & 920 & 13 & 14677 & 2717 & 17 & 14677 & -963 \\
\hline 5 & JANUARI & 920 & 13 & 14937 & 2977 & 17 & 14937 & -703 \\
\hline 6 & FEBRUARI & 920 & 13 & 15218 & 3258 & 17 & 15218 & -422 \\
\hline
\end{tabular}

Sumber : Hasil Analisis, 2020

\section{KESIMPULAN}


Peningkatan jumlah penumpang pada pukul 18:00 - 19:00 WIB dari bulan September 2019 - Februari 2020 sebesar $104 \%$. Dengan waktu tempuh 30 menit dan waktu peredaran sarana 10 menit. Dengan headway 5 menit dengan kebutuhan armada sebanyak 14 stamformasi dan jumlah perjalanan sebanyak 19 perjalanan. Peningkatan jumlah penumpang pada pukul 19:00 - 20:00 WIB dari bulan September - Februari 2020 sebesar $120 \%$. Pada pukul 19:00 - 20:00 WIB dari headway 10 menit dapat di perkecil menjadi headway 7 menit dengan jumlah perjalanan sebanyak 13 perjalanan. Perlu menambahkan kecepatan rata - rata sebesar 80 - $90 \mathrm{~km} / \mathrm{jam}$ sehingga dapat mempersingkat waktu tempuh dari waktu tempuh 30 menit menjadi 28 menit pada pukul 18:00 20:00 WIB. Untuk memenuhi kebutuhan operasi pada jam sibuk dengan headway 5 menit terutama pada pukul 18:00 - 19:00 WIB perlu adanya penambahan dari 19 perjalanan menjadi 21 perjalanan. Dan diperlukan juga penambahan jumlah kebutuhan sarana dari 10 stamformasi menjadi 14 stamformasi sehingga penumpang yang tidak terangkut dapat terangkut semua. Perlu adanya perubahan headway dari 10 menit menjadi 7 menit pada pukul 19:00 - 20:00 WIB. Dan juga diperlukan penambahan jumlah perjalanan dari 13 perjalanan menjadi 17 perjalanan dengan penambahan kebutuhan sarana siap operasi dari 7 stamformasi menjadi stamformasi sehingga penumpang yang tidak terangkut dapat terangkut semua.

\section{DAFTAR PUSTAKA}

Abbas, Salim. 2000. Manajemen Transportasi. Cetakan Pertama. Edisi Kedua Ghalia Indonesia. Jakarta.

Miro, F. 2005. Perencanaan Transportasi Untuk Mahasiswa, Perencana, dan Praktisi. Erlangga. Jakarta.

Nasution. 2008. Manajemen Transportasi. Ghalia Indonesia. Bogor. Komaruddin. 2001. EnsiklopediaManajemen, Edisi ke 5. Bumi Aksara. Jakarta.

Harahap, Sofyan Syarif. 2004, Analisis Kritis Atas Laporan Keuangan. PT Raja Grafindo Persada. Jakarta.

Alim, Syahrul. 2014. Analisis Pengaruh Inflasi dan BI rate terhadap Return on Asset (RoA) Bank Indonesia. Jurnal Ekonomi Modernisasi. Jakarta.

Anne, Gregory. Perencanaan dan Manajemen Kampanye Public rlations.

Erlangga. Jakarta.

Darminto, Dwi Prastowo dan Rifka Julianty. 2002, Analisis Laporan Keuangan : Konsep dan Manfaat. AMP-YKPN. Yogyakarta.

Umar, Husein. 2002. Metodologi Penelitian Aplikasi dalam pemasaran. PT Gramedia Pustaka Utama. Jakarta.

Afdi Nizar, Muhammad. 2012. Dampak Fluktuasi Harga Minyak Dunia Terhadap Perekonomian Indonesia. Badan Kebijakan Fiskal, Kementrian Keuangan-RI. Jakarta.

Supriadi, Uned, 2008, Perencanaan Perjalanan KA Dan Pelaksanaannya, PT. Kereta Api (Persero), Bandung.

Supriadi, Uned, 2008, Kapasitas Lintas Dan Permasalahannya. PT Kereta Api (Persero), Bandung. Winardi, Aris, 2014, Analisis Kapasitas Lintas pada Lintas Medan - Araskabu Terkait dengan Operasi Kereta Api Bandara. Sekolah Tinggi Transportasi Darat, Bekasi.

Zuliyanto, Agus Muhammad, 2017, Analisis Peningkatan KA Lokal Bandung Raya Guna Mengatasi Lonjakan Penumpang Pada Dua Jam Sibuk Pagi Di Stasiun Cicalengka Cimekar, KKW, A.Md. KA, Jurusan Perkeretaapian, Sekolah Tinggi Transportasi Darat, Bekasi.

Ilham, Dicka, 2017, Analisa Rencana Pola Operasi LRT Lintas Kelapa Gading 
- Velodrome Rawamangun, KKW, A.Md. KA, Jurusan Perkeretaapian, Sekolah Tinggi Transportasi Darat, Bekasi.

Astuti, Diah Puji, 2018, Analisis Penambahan Kereta pada Stamformasi KA Lokal Dhoho Guna Mengangkut Penumpang Tidak Terangkut Di Lintas DAOP 8 Surabaya, KKW, A.Md. KA, Jurusan Perkeretaapian, Sekolah Tinggi Transportasi Darat, Bekasi. 